\title{
The lightwave roadshow
}

\section{Hannah Foreman, Francesca Parmigiani, Michaël Roelens, Robert Simpson}

Hannah D. Foreman, Francesca R. Parmigiani, Michaël A. F. Roelens, Robert E. Simpson, "The lightwave roadshow," Proc. SPIE 9664, Ninth International Topical Meeting on Education and Training in Optics and Photonics, 96641U (24 October 2005); doi: 10.1117/12.2207693 and Photonics, 2005, Marseille, France 


\title{
Ref ETOP035
}

\section{The Lightwave Roadshow}

\author{
Hannah D. Foreman ${ }^{1}$, Francesca R. Parmigiani' ${ }^{2}$, Michaël A. F. Roelens ${ }^{2}$, Robert E. Simpson ${ }^{2}$. \\ ${ }^{1}$ School of Physics and Astronomy, University of Southampton, Southampton, UK. \\ ${ }^{2}$ Optoelectronics Research Centre, University of Southampton, Southampton, UK.
}

\begin{abstract}
Many primary school children perceive science as boring and inaccessible. These misconceptions mould the paths these children will choose for their future education and careers, mirrored in reducing numbers of applicants for physics courses in higher education. We describe our experiences running a photonics outreach project, The Lightwave Roadshow, an interactive collection of photonics demonstrations and experiments aimed at children aged 5 to 11. We discuss how this programme can be instrumental in improving the profile of scientific education and careers for children of a young age.
\end{abstract}

\section{Introduction}

It is widely recognised that a child's negative image of an archetypal scientist begins to form at a young age [1]. It is believed that this negative image can influence a child's choices in education path and hence career [2], as seen in the current decline in the number of students choosing to study physics after the age of 16 [3]. Indeed, recent research has shown that the opinions and aspirations held by 11-year-old children towards post-compulsory education are unlikely to change by age 16 [4]. The following paper describes the use of an interactive Roadshow to

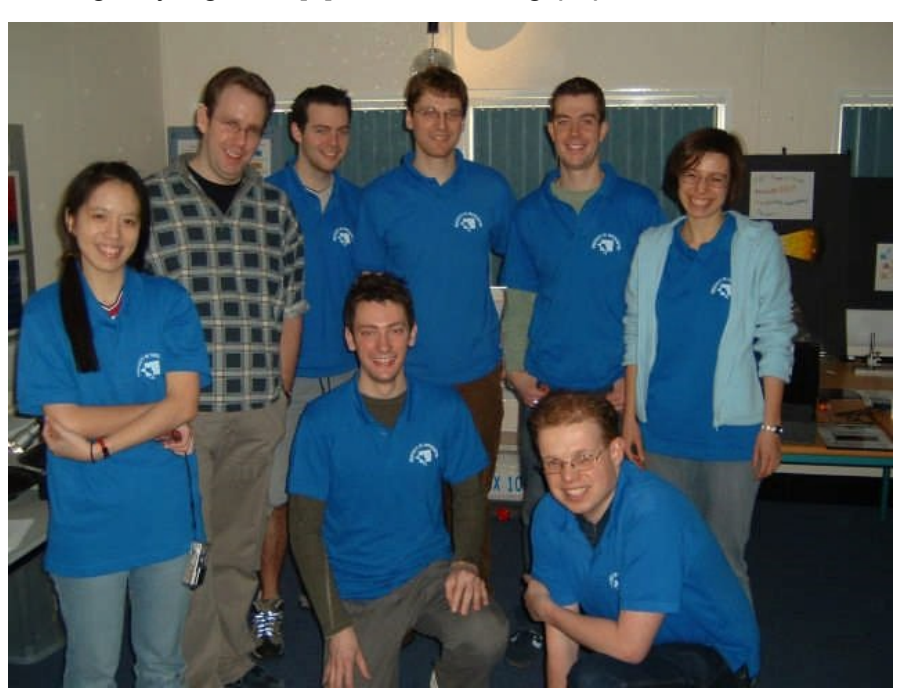
communicate basic photonics concepts to primary school children (aged 5-11), and improve the image of physics and higher education in science to this impressionable age group during these important formative years. The Lightwave Roadshow is run by postgraduate volunteers from the Optical Society of America (OSA) Student Chapter based at the University of Southampton [5]. We will outline the benefits and the problems of running these sessions at local primary schools, community events and science fairs.

Figure 1: Lightwave volunteers from the Southampton University OSA Student Chapter 
Some of these challenges include communicating effectively with a mixed group of children, supplying a range of practical activities and experiments that cater for their diverse abilities, time and equipment limitations, and the challenge of coordinating a session. The benefits of this scheme, which we believe far outweigh the problems, include the pupils' improved knowledge and understanding of basic optical concepts, the opportunity for us to challenge negative perceptions of science and motivation, increased interest in science, and the opportunity for pupils to meet active researchers from the University community.

\section{Background and program}

The University of Southampton Student Chapter of the OSA was established by postgraduate students from the Optoelectronics Research Centre in 1994, later joined by postgraduate students from the University's School of Physics and Astronomy. It was the first international student chapter of the OSA. The goals of the chapter are to increase and disseminate knowledge of optics, promote technical activities in optics, broaden student's insight into management and organizing technical activities, encourage interaction between students, further links with the optics community and to promote the expertise of optics and photonics PhD students. Within this remit, in 1998, the Lightwave Roadshow was established by volunteers from the chapter. The OSA provides annual outreach grants of $\$ 500$ to its student chapters, which is dedicated to Lightwave by the Southampton Chapter. Using this money, we have developed and expanded the show, designed and built new equipment (augmented by a few items acquired from the University), and published a successful interactive website [6].

The Roadshow targets primary school children aged 5-11, and consists of 6 sections for them to visit: the eye, mirrors, lenses, the spectrum, communication with light and 'hands on'. The session allows groups of children to move from topic to topic, and can be tailored to any length of time from 30 minutes to 3 hours. Group sizes vary from 20 to 60 children. The Roadshow also works well as an informal display at a science fair or open day [7]. The show is mobile, so visiting local schools and community centres is also possible, with requirements kept simply to 6 good-size tables for the sections, and a room to house these and three more bulky demonstrations, a large classroom, small sports hall, or teaching lab is ideal.

\section{Topics and activities covered}

Lightwave's mascot is Phil Photon, a red cartoon we use to help children to grasp the idea that light is a wave consisting of particles of light called photons. The use of a mascot in this way provides a fun and memorable medium through which to explain many fundamental principles within optics and photonics. The equipment accumulated for the Roadshow is divided into six logical sections, detailed below.

\section{The Eye}

This section of the Roadshow aims to communicate the message that we use our eyes to see
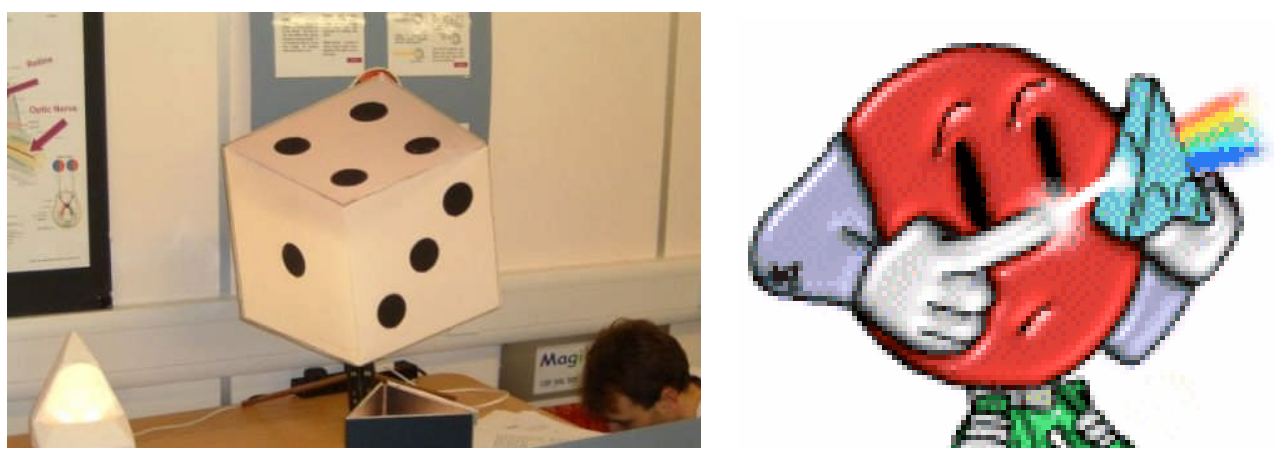

Figure 2: a) 'The Cube' optical illusion demonstration in the eye section and b) Phil Photon,

Lightwave's mascot. 
light. The idea of the eye as a light detector is enough to grasp for younger children, but to take the topic further, we use a working model of the eye to focus images of Phil photon onto a false retina. The eye model has a variable liquid-filled lens, corresponding to that of the human eye. The children are given the opportunity to change the focus for themselves using a connected syringe. The retina distance from the lens can also be changed to demonstrate long and short sightedness, and lenses may be slotted in front of the eye like glasses to correct the image. Volunteers explain to the children how their brain works in conjunction with their eyes for them to see. To demonstrate this, a series of optical illusions are shown. These include a large 3D cube model which, when lit from below appears to 'stick out' even though it is hollow, demonstrating how our brains expect things to be lit from above, and cast shadows accordingly. Also within this section children perform experiments to find their blind spot, play with an array of magic eye pictures, and common optical illusions.

\section{Mirrors}

The concept of reflection is very new to most Lightwave attendees, indeed some are too young to be expected to grasp it. So, an important emphasis is placed on playing with the equipment. Whilst the younger audience play, the older children are encouraged to discuss the physics behind what is happening.

The equipment for the section includes sets of hinged flat mirrors used to reconstruct quarter and half images on shape cards. There are sets of 2 parabolic mirrors that we use to produce an image of a plastic pig $5 \mathrm{~cm}$ above its actual position. The children try to grab the image, their curiosity sparked as they are left empty handed, a perfect precursor to discussion and explanation of the 'magical' physics behind this trick. A set of flexible mirrors is used in the 'make yourself look ugly' experiment where children distort their reflections. The periscope is introduced here, and children are encouraged to think about paths of light. We draw the analogy of Phil photon running towards mirrors and bouncing off.

This section also boasts two 'house of mirrors' style displays, the Homogeniser and the Triadis. The Homogeniser is a human kaleidoscope large enough for 4 children to use at once, they put their heads in at either end and look at each other's multiple reflections, a very popular demonstration. The Triadis consists of a triangular array of mirrors that a group of 3 or 4 children stand within, and observe their multiple reflections again.

Lenses

Children are very familiar with lenses in their every-day life, but not the concepts behind their operation. The equipment for this section includes a box of common lenses, such as eye glasses, camera lenses etc. the children are encouraged to
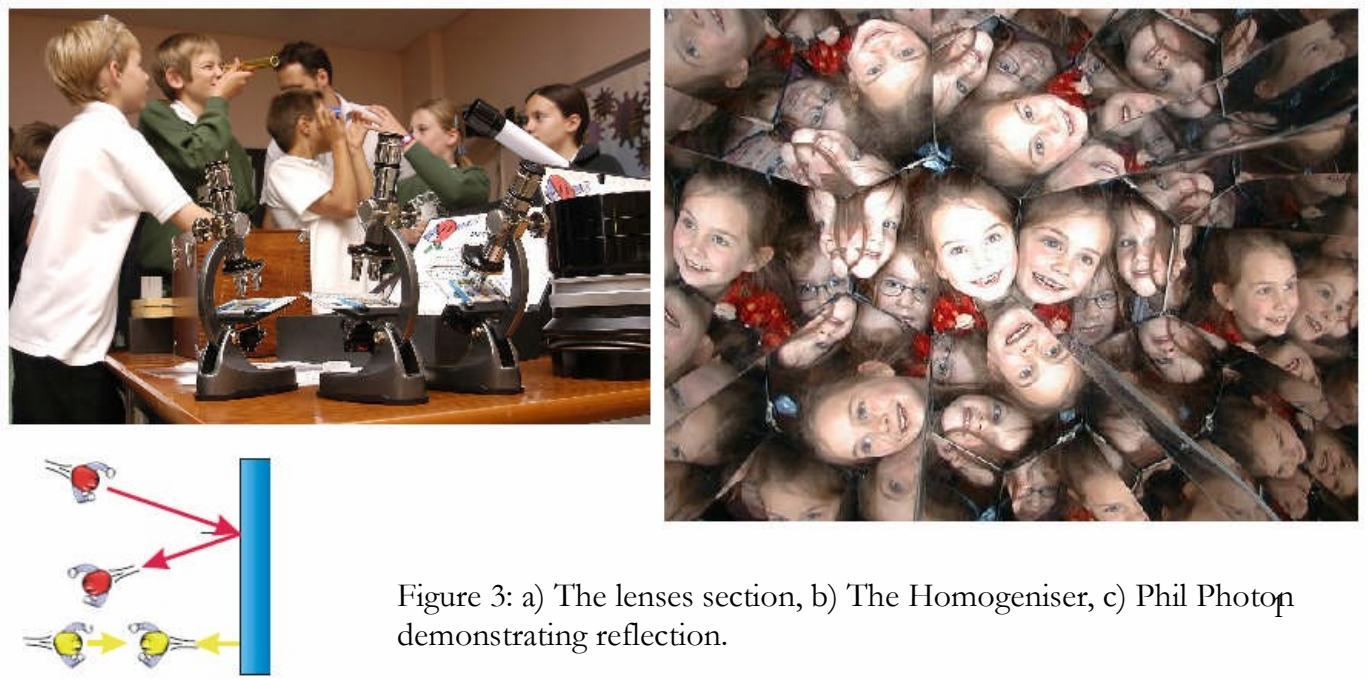

Figure 3: a) The lenses section, b) The Homogeniser, c) Phil Photon demonstrating reflection. 
sift through the box, playing with the various items, focussing images and wearing the array of spectacles as fancy dress. This fun introduction to the section forms a great environment in which to discuss how lenses work. The children may already have experienced lenses in the eye section and focussing within the mirror section, they are encouraged to draw on this experience. A large camera lens that is too heavy for the children to lift often generates great curiosity. A selection of Fresnel lenses, less familiar to the children, is shown, and their diverse applications explained. Finally, the children are encouraged to play with a selection of microscopes and telescopes.

\section{The Spectrum}

At primary age, children are very familiar with the colours in their paint box, many have painted pictures of rainbows, and mixed primary paint colours to create other colours. However, the idea that white light is composed of many different colours of light from the whole spectrum is often alien to them. Indeed, this is a difficult concept to grasp since it is not analogous to the familiar mixing of paint, but it is a concept that is fundamental to optics and photonics. In the spectrum section, children are encouraged to experiment with light of different colours to help them to accept and understand.

The equipment for this section focuses on splitting up white light into its constituent colours and recombining it to form white light again. Sheets of diffraction grating are used to separate white light from room lights and torches out into its constituent colours. The spectrum obtained is compared with that produced by the light from a red diode laser, which appears only red behind the diffraction grating. The back of a CD acts as a good diffraction grating also, and children are encouraged to look at spectra from light sources at home using an old CD. Torches and interchangeable coloured filters are used to create light of various colours, which is then recombined to create white light, and other colours. The children are encouraged to play with colour wheels, trying to spin a wheel decorated with the whole spectrum to recombine the colours and make white.

The children are also introduced to the spectrum beyond the visible. Infrared light is talked about as 'heat ' and infrared camera images of various every-day objects are shown to demonstrate this light that the children cannot see. Ultra-Violet (UV) light is the real showcase of this section. A dark area is created in one corner of the room, or under a table using a black cloth, 2 UV lamps are placed inside. Items that fluoresce when illuminated with UV are

distributed about the 'cave'. These consist of bottles of tonic water, which contains a fluorescing

mineral, fluorescing security tagged items, various plastics, and rocks coated with a florescent paint. The children crawl inside with a volunteer, and watch with great excitement as any white items of clothing, teeth and eyes fluoresce. UV fluorescing pens are used to create secret

pictures, and the children can play with the florescent objects.

\section{Communicating with light}

A key application of optics and photonics is telecommunications, indeed, the Optoelectronics Research Centre (ORC) at Southampton University prides itself on being a leader of innovation in this field. The communicating with light section aims to raise the child's awareness of the advantages of the use of light for communication, and just how much of their everyday life is influenced by this. Discussion is initiated about the Internet, cable TV, and trans-Atlantic phone calls all of which rely on optical communication. Older forms of light communication, such as Morse code and smoke signals, are discussed. The children send short messages to each other across the room using a light bulb and Morse code. Then, the children are reminded that light only travels in straight lines, raising the question of how it can be communicate around corners, let alone across the Atlantic ocean. A small model consisting of an infrared transmitter and receiver with a straight path, transmitting and broadcasting a musical signal is used to show that if we block the beam (using a model of a house), the signal cannot pass. The children are then introduced to Tyndall's experiment, guiding light from a laser pointer down a stream of water. Within the water stream, the children can see the light totally internally reflecting. If they put their hands into the stream, they see the red light scatter from a spot on their hand. At this point, optical fibres are introduced, and the concept that light travelling along them is totally internally reflecting, or 'bouncing' back and forth inside the fibre is introduced. An optical fibre is introduced to the transmitter model, and the signal is guided around the blocking house to broadcast the signal. Various fibre-optic lamps and toys are used to encourage the children to investigate and understand this principle further, and the analogy of Phil Photon running along a tunnel is drawn. Finally, the fabrication of optical fibre is explained to the children, they are shown a roll of fibre, and 


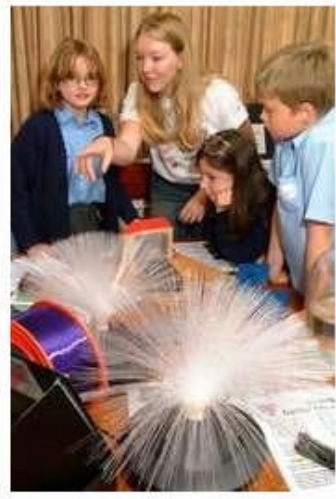

Figure 4: Images from the communicating with light section.

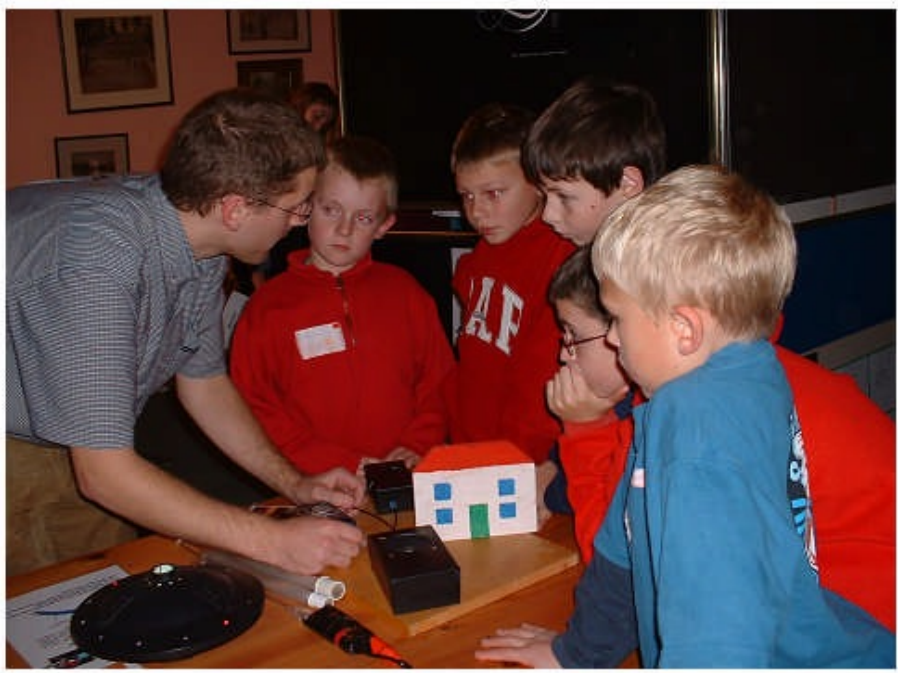

encouraged to touch, test its strength, and guess its length. They are also shown a fibre perform, within which torchlight is guided, and the drawing process is explained.

'Hands On'

The 'hands on' section gives children the chance to make their own optical toys to take away as a reminder of their Lightwave experience. The participants are supplied with all the materials they require, including sheets of card photocopied with simple outlines to cut around and fold. Under the supervision of an OSA volunteer, the children make either a simple periscope, or an optical illusion cube. Small mirror tiles from a DIY shop are used for the ends of the periscope, and the cube is under lit with a desk lamp in the same manner as the analogous illusion encountered in the eye section. This section is very popular with the young audience. We hope that the toys the children take away with them will act as reminders of the Lightwave experience, and its positive message about science. Furthermore, it is hoped that the children will show the toys to their parents, sparking discussions at home about science and educational aspirations.

\section{The challenges}

The main challenges for Lightwave arise from its voluntary nature. No member of the team, including the Roadshow coordinator is paid in any way for his or her time. As postgraduate students, there is in fact little incentive to volunteer, and with pressing demands on their time, few can afford to spare an afternoon, or sometimes even a whole day. This also has implications for maintenance of the equipment. The Roadshow relies solely on the willingness of a keen group of enthusiastic individuals to donate their time. Furthermore, the act of explaining very basic physical concepts to young children is a daunting task in itself, and can be a deterrent for potential volunteers. 
As with any scheme of this nature, challenges arise from the issues of communicating with an audience of mixed ability. This challenge is particularly prevalent in shows where the audience is of a mixed age, especially at events such as science fairs, where accompanying adults may have their own, more advanced questions. To overcome this issue, the audience is split into small groups of 5-10 children. Within these groups, it is easier for the supervising volunteer to ensure that every child's needs are met, and that they can enjoy each experiment at their own level.
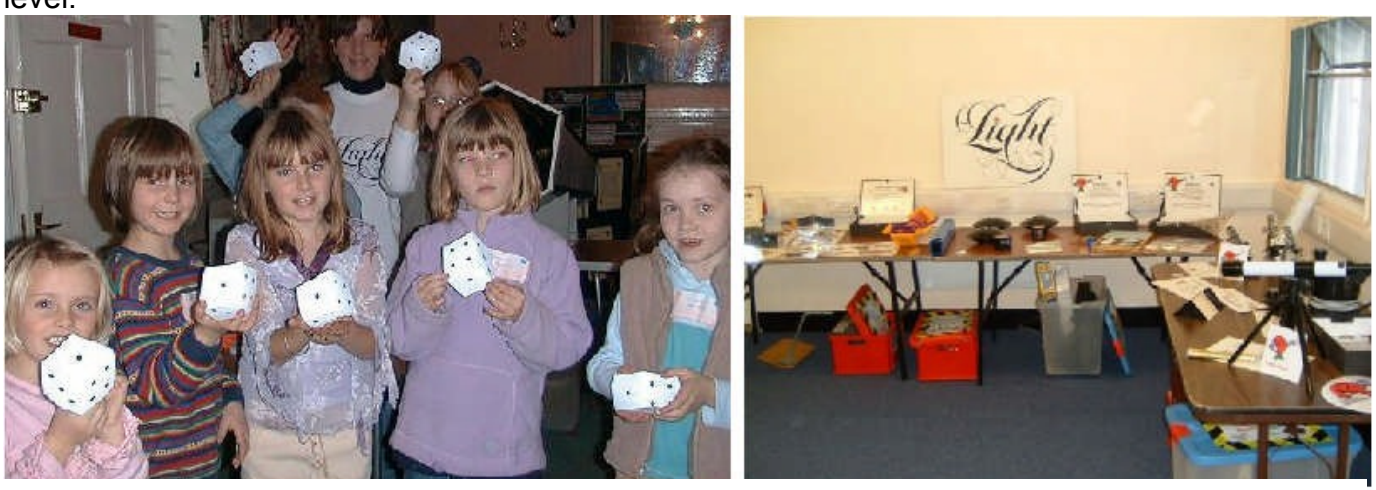

Figure 5: a) Results of the 'hands on' section, and b) the Lightwave kit.

To avoid a false perception of the sessions as inaccessible, the fun element of each experiment is concentrated upon. No child is forced to take part anymore than they wish, but experience has shown that this is not a frequent problem, since few attendees can resist playing. It is important to avoid alienating an enthusiastic audience with the use of too many technical terms. Colloquial language used, and elaborate scientific terminology is avoided. Phil photon helps to overcome this problem by acting as a medium through which to describe the more difficult concepts forming analogies with experiences that the children have in everyday life.

A further challenge lies in providing a selection of equipment to cater for this range of ages and abilities. The Roadshow kit consists of a collection of various optics demonstrations and toys gathered over time. Volunteers have constructed some of the larger pieces, funded by the small grant from the OSA. The kit is presented in a way that focuses on the fun elements of each piece. For younger children, to play with the kit is enough, and it is hoped that the memories of the enjoyable time they had will be associated with science and further education in years to come thus positively influencing the child's attitudes towards them. For older children, playing with the kit is used as a platform on which to build discussion about the physical principles behind its operation. These two different approaches to utilizing the kit allow the least sophisticated of toys to appeal to the whole audience, and no item is left redundant.

In order to appeal to a wide range of establishments and venues, and provide flexibility around the tight scheduling of the national Curriculum, Lightwave is not publicised with any time constraints. Consequently, requests are made for shows of various lengths. The challenge of tailoring the show from a 30-minute event to something that can occupy a whole morning or afternoon session is overcome by both the flexibility of the volunteers, and the simplicity of the kit. With ample volunteer supervision at each section, time spent on each activity is easily stretched or compressed as desired by varying the depth of discussion. 
The Lightwave organiser has the additional challenge of coordinating the whole diary of events. They must arrange dates with the hosting body, coordinate publicity, recruit a team of willing volunteers, arrange refreshments, and ensure that the kit's stock of consumables is replenished adequately. At each event, experience has shown that it is most efficient to have an overall supervisor. This person is responsible for watching time, and ensuring that the groups move from one station to the next on time. They are also responsible for solving any problems that may arise, and dealing with any general queries from accompanying adults.

The nature of the Lightwave Roadshow dictates that the equipment must be mobile, and that any problems can be solved on site at an event. The team of volunteers are adequately skilled to solve any technical problems that may arise, so it is simply ensured that they have all the resources available to them for them to do so. A toolbox is always carried, along with plenty of various adhesive items, cleaning tools, spare batteries etc.

A further limitation of Lightwave is our ability to gauge how successful it has been in fulfilling our goal of changing negative perceptions of science and higher education, and encouraging children to pursue science in education, and later careers. Without considerable funding, it is impossible to track the paths of the attending children through life, and carry out any real research into whether or not the Roadshow actually has any effect. We receive much positive feedback from teachers and other hosts, and the volunteers at each section are able to gather some basic feedback from the children about their experience, but any sort of formal questionnaire is not feasible.

\section{The benefits}

A clear benefit of this scheme is the opportunity to provide children with a session dedicated to the subject of optics and photonics. The time and budget pressures upon primary school teachers to cover the broad range of topics within the National Curriculum [8] in the classroom make sessions involving lots of demonstrations of this nature impossible to include normally. The Roadshow makes it possible to hold such a session. It is hoped that as a result of attending the Roadshow, pupils' knowledge and understanding of basic optical concepts will be improved. Lightwave provides a forum for practising scientists to challenge negative perceptions of science and scientists that children form at a young age. The Roadshow volunteers are young, vibrant, enthusiastic individuals, passionate about their subject, and communicating it to others. A conscious effort is made to include female volunteers. We are confident that the positive, fun, inclusive atmosphere created demonstrates that science and more specifically, optics and photonics, is accessible to everyone. The everyday examples of applications of optics and photonics given demonstrate to the children the wide scope of the topic, and just how much of our everyday life is affected by it.

Moreover, the Roadshow provides a rare opportunity for primary school children to meet active researchers from the University community. Often, the schools visited are within the locality of the University of Southampton itself, but alarmingly, the children have little insight into the University's function. Lightwave acts as a showcase for the University. Postgraduates talk freely about their life at University, and about their education and research experiences, the children have a chance to ask questions. The University of Southampton, and the Southampton University Students Union are dedicated to forging links with the local community, and maintaining a harmonious relationship [9]. The Lightwave Roadshow supports this end, breaking down some of the mystique that surrounds higher education, and providing a bridge between the University and the wider community. 
The experiences that the children have during the Roadshow aim to increase the children's interest in science. It is hoped that following a Lightwave visit, children's motivation for science in the classroom and indeed at home is increased. Moreover, volunteering to supervise at a Roadshow event can be a very motivating experience for the postgraduate recruits. The opportunity to communicate their subject in an enthusiastic, fun environment, and see the positive reactions of the children has proved to be a very fulfilling experience. Most volunteers see the satisfaction and transferable skills gained in taking part as an adequate reward for their time. The Roadshow provides a unique opportunity for postgraduates to work in a team with their peers in a fun environment without the stresses of day-to-day lab work, and the events are usually very enjoyable.

\section{Conclusion}

We have demonstrated an interactive Roadshow, run by a keen volunteer base, aiming to generate enthusiasm in primary school children for topics in optics and photonics. A broad spectrum of subjects within optics and photonics is covered, providing a forum for children to increase their understanding of basic principles in optics and photonics. However, its scope is much broader, offering an opportunity for the image of science, scientists and further education to be improved not only with this group of young children, but also in the wider community. It provides a rewarding, motivating experience for both the children attending and the postgraduates volunteering to supervise.

\section{References}

1. K. D. Finson, Drawing a Scientist: What We Do and Do Not Know After Fifty Years of Drawings, School Science and Mathematics, 102\#7, pp 335-346, (2002)

2. K. J. Topping, C. Peter, P. Stephen and M. Whale, Cross-Age Peer Tutoring of Science in the Primary School: Influence on scientific language and thinking, Educational Psychology, 24 \#1, (2004)

3. K. H. Elliott, Physics With Everything, Eur. J. Phys., 24, Editorial, (2003)

4. P. Croll, The Formation and Transmission of Educational Values and Orientations, ESRC award R000239963 (2005)

5. Southampton University OSA Student Chapter, www.orc.soton.ac.uk/OSA

6. The Lightwave Roadshow, www.lightwave.soton.ac.uk

7. H. Foreman, Lightwave at Chiddingstone Castle, Focal Point, Winter 2003 edition (2003)

8. Qualifications and Curriculum Authority, The National Curriculum Online, www.nc.uk.net

9. University of Southampton Student Community Action, www.action.susu.org

\section{Acknowledgements}

The authors would like to thank the many postgraduate members of the Southampton University OSA Student Chapter who have volunteered their time to Lightwave over the years.

*hdf@phys.soton.ac.uk, tel: +44 (0)23 8059 2066, fax: +44 (0)23 80593910. 